\title{
EL CONCEPTO DE CORRECCIÓN IDIOMÁTICA: LO "RECTO", LO USUAL Y LO EJEMPLAR EN LA PRÁCTICA DEL IDIOMA ${ }^{1}$
}

\author{
J. Javier Mangado Martínez \\ Universidad de La Rioja
}

\begin{abstract}
RESUMEN: La polisemia de los términos correcto/incorrecto, referidos al uso del idioma, induce a confusiones indeseables. En consecuencia, hay que distinguir los conceptos diferentes subsumidos en ellos. A esa distinción dedica el autor este trabajo: parte de la concepción de Coseriu, incorpora las ideas recientes sobre el tema y aporta un nuevo concepto muy útil al respecto, al que llama lo "recto", oponiéndolo a lo usual y a lo ejemplar ya fijados. En el uso del idioma lo correcto es lo normal. Una realización idiomática puede pertenecer a lo normal por dos motivos: por estar construida de acuerdo con los cánones del sistema de la lengua correspondiente (es decir, por ser recta), o por ser usual en la comunidad lingüística donde se emite. Puesto que las comunidades lingüísticas presentan entre sí diferencias evidentes, se necesita una norma estándar, la ejemplar, que, dentro de la misma lengua, facilite la comunicación intercomunitaria. Dado que la variedad lingüística que se adquiere de forma natural no es la intercomunitaria, sino la intracomunitaria, se hace imprescindible estudiar la norma ejemplar para conocerla y fijarla. La lingüística normativa, la encargada del estudio de la lengua estándar, cobra así razón de ser y justificación científica.
\end{abstract}

ABSTRACT: The Polysemy of the terms correct/incorrect, referring to the use of language, leads to unwanted confusion; accordingly, the different

1. Los cimientos de las ideas que voy a desarrollar aquí se deben a Eugenio Coseriu, sin duda uno de los mejores lingüistas de todos los tiempos, recientemente fallecido en detrimento de la ciencia lingüística. Partiré de su concepción al respecto recogiendo, claro está, las aportaciones y actualizaciones posteriores, entre las que destacan los trabajos de M. Alvar, A. Gallardo, C. Hernández o L. F. Lara, y, de manera especial, las múltiples ponencias relacionadas con este tema presentadas en el II Congreso Internacional de la Lengua Española celebrado en Valladolid en octubre de 2001, sobre todo las de J. M. Blecua, V. Demonte, S. Gutiérrez Ordóñez, C. Hernández, M. Lope Blanch, M. a Antonia Martín Zorraquino y A. Narbona. Todas estas referencias se encuentran detalladas en la "Bibliografía" final. En lo que se refiere a conceptos, mi mayor aportación consiste en la idea (y el término) de "lo recto". 
concepts subsumed in them should be distinguished. To this distinction this paper is dedicated: starting from Coseriu's conceptions, the author incorporates current ideas on the subject, and contributes a new useful concept, what he terms the "recto", in opposition to the usual and to the ejemplar, terms already accepted and in general usage. In the use of language what is correct is the normal. An idiomatic phrase may belong to the normal for two different reasons: because it has been formed in accordance to the cannons of the given language system (that is because it is recta), or because it is usual in the linguistic community where it is articulated. Given that linguistic communities show obvious differences among themselves, a standard norm is necessary, the ejemplar, which, within a specific language, facilitates intercommunity communication. Since the linguistic variety which is naturally acquired is not the intercommunity, but the intra community one, it becomes necessary to study the exemplary norm and to secure it. Thus, normative linguistics, in charge of the study of standard language, takes on special meaning and scientific justification.

\section{Objetivos de este trabajo:}

1. Distinguir y precisar los conceptos, bien diferentes, que, por soler englobarse bajo el término (in)corrección idiomática, inducen a confusiones indeseables.

2. Justificar la entidad de la lingüística normativa, perfilar el lugar que ocupa en la ciencia lingüística y encarecer la necesidad de su estudio.

\section{INTRODUCCIÓN}

El lingüista alemán H. Schuchardt dejó escrito: "La imprecisión terminológica es para la ciencia como la niebla para la navegación. Y, por supuesto, es tanto más peligrosa cuanto más ignorante se es de su existencia".

Pues bien, de esa imprecisión adolece el término (in)correcto para referirnos a hechos y fenómenos lingüísticos, un término usualmente polisémico que abarca valores semánticos bien diferentes. No parece, en efecto, que haya que asignar el mismo grado de incorrección, ni la misma naturaleza conceptual siquiera, a casos a los que suele colocarse la etiqueta de "incorrectos", como los siguientes: "aver" haber), "me se cayó" (V se me cayó), "recepcionar" (V recibir), "echar una instancia" ( presentar una instancia), "dar un óvulo" (/ dar un óbolo), "deflagración" (V explosión), "cantao" (/ cantado), “iquién eres tú?" (V ¿quién es usted?) o "metiera" (V metió)... ¿Y qué pasa con los dialectalismos?: ¿son incorrectos? ("Aquí hablamos muy mal", suelen asegurar quienes usan a diario, por ejemplo, "canilla" por grifo, "canucirse" por enmohecerse, "aldraguero" por entrometido, "chandrío" por estropicio, "chozne" por pan hueco...). Muchas personas, cuando se enteran, se asombran de que formas como toballa o andalia figuren en el DRAE: ¿esa inclusión las convierte automáticamente en correctas? ¿Toda palabra que no se encuentre en el $D R A E$ ("ustedear" 'tratar de usted', por ejemplo) ha de considerarse por eso incorrecta? Y si en el DRAE aparecen dos o más versiones de una palabra (como extravertido/extrovertido, o repantigarse/repantingarse), ¿puede decirse que una es más 
correcta que (la) otra?; en su caso, ¿cuál? ¿Es correcto el seseo?, ¿y el voseo?, ¿y el yeísmo? Todas estas cuestiones encontrarán respuesta satisfactoria si ordenamos nuestras ideas a la luz de quienes han reflexionado profundamente sobre ello.

La polisemia del término (in)correcto, mediante la mezcla de sus elementos, origina confusiones. Como puntualiza Coseriu², se confunde la "lengua ejemplar" con el "juicio de corrección"; el "juicio de corrección idiomática" con otros juicios; y [lo que más nos interesa en esta ocasión] lo correcto con lo ejemplar en un doble sentido: 1) reducción de lo correcto a determinada ejemplaridad, y 2) reducción de lo ejemplar a lo simplemente correcto.

Lo primero (reducción de lo correcto a determinada ejemplaridad) es propio de los conservadores o puristas. Abogan por una unidad idiomática estricta total caracterizada por la estaticidad (la lengua ya está fijada y lo demás, como suelen decir, "no existe"), por la homogeneidad (un único sistema) y por la exclusividad (sin niveles ni registros) $)^{3}$. Lo segundo (reducción de lo ejemplar a lo simplemente correcto) caracteriza a los liberales o tolerantes. Éstos rechazan por inútil cualquier actividad en pro de una presunta unidad idiomática, porque para ellos sólo el uso debe imponer su autoridad. Es decir, para los segundos todo vale si se usa; para los primeros sólo vale lo que tradicionalmente han usado los mejores y sólo tal y como lo han usado. Ambas posturas extremas tienen algo de razón y mucho de criticable.

A los ultraconservadores hay que recordarles que, como veremos más adelante, la lengua es dinamismo (no estaticidad) y que integra varios sistemas (es un diasistema) y una pluralidad de normas. A los ultraliberales hay que hacerles ver que la unidad idiomática constituye un problema real; que lo ejemplar tiene validez como cohesión y hecho de cultura; que una planificación lingüística bien entendida es razonable; y que la falta de normas [sociales, en general, y lingüísticas en particular] no sólo no resulta progresista, sino que -como afirma Coseriu- conduce a la barbarie $^{4}$ : prescindir de las normas idiomáticas (si tal fuera posible) constituiría, en efecto, algo tan incivilizado y antisocial como, por ejemplo, independientemente de las consecuencias, pretender circular con un coche por la izquierda en Logroño, o por la derecha en Londres, alegando derecho a la libertad individual ${ }^{5}$.

Por otra parte, el problema de la (in)corrección idiomática interesa a los ciudadanos: resultan hechos muy significativos al respecto la abundancia actual de bibliografía de carácter normativo, que el DRAE o El dardo en la palabra alcancen la categoría de superventas, o el éxito de la sección de dudas en la rae.es. Paradójicamente, se lamenta Coseriu ${ }^{6}$, constituyendo éste el problema lingüístico más interesante para el hablante, es el de menos interés para el lingüista.

2. COSERIU, E. (1990), pp. 45-46, y (1992a), pp. 4-5.

3. COSERIU, E. (1990), p. 46.

4. COSERIU, E. (1992a), p. 2.

5. Tildaríamos de loco a alguien que, por ejemplo, se empeñara en Ilamar árbol a la 'ventana', nube al 'bolígrafo', vaso al 'papel', cantar a 'anochecer', después a 'ayer'... En cambio, agradecemos que alguien tenga la gentileza democrática de llamar al 'pan' pan y al 'vino' vino.

6. COSERIU, E. (1992a), p. 1. 
El profesorado, el de todos los niveles educativos, suele alinearse en uno de los dos bandos (conservadores / liberales), a veces furibundamente. Y, quiéralo o no, su actitud antitética transmite confusión a sus alumnos y a sus compañeros, los cuales a su vez la propagan en cadena. Eso ocurre - no me cabe ninguna duda- porque entienden por correcto cosas muy distintas. Estos tres aspectos patentes (la confusión conceptual, el interés social y la trascendencia educativa) hacen que merezca la pena que reflexionemos al respecto con hondura.

\section{LO CORRECTO ES LO NORMAL: LO USUAL}

El DRAE vigente (2001) define así correcto: "Dicho del lenguaje, del estilo, del dibujo, etc...: Libres de errores o defectos, conformes a las reglas" (ac. 1). Definición prescriptiva tradicional que sólo nos interesa aquí en cuanto testimonio de la restricción del concepto. Mayor interés ofrece la del $D E A^{7}$ : "Que se ajusta a la norma o modelo considerados válidos en un campo determinado". Definición abierta y objetiva que se centra en el concepto clave de este asunto: la norma. ¿Pero qué es la norma? Se han fijado dos maneras de entender esta noción: la prescriptiva (y proscriptiva), es decir, la que indica qué debe decirse y qué no, y la objetiva ${ }^{8}$.

La perspectiva prescriptiva-proscriptiva entiende la norma como una imposición de modelos de corrección, de un uso determinado como el más adecuado y prestigioso. Es rechazada por los lingüistas por considerarla ajena a la objetividad científica. A. Narbona ${ }^{9}$, por ejemplo, nos recuerda que sólo las normas ortográficas pueden calificarse de "obligado cumplimiento", y V. Demonte ${ }^{10}$ niega que pueda hablarse de "hechos erróneos" al referirse a las "desviaciones" sintácticas hoy frecuentes que pueden explicarse perfectamente dentro de la "gramática de la variación sintáctica" no distinguible de la normativa.

La prescriptiva constituye la perspectiva tradicional. El punto de inflexión en el devenir histórico lo originó, como explica S. Gutiérrez, el estructuralismo: «En el pensamiento del lingüista estructural no es operativo el eje de valoración correcto/incorrecto. Como consecuencia, el término norma queda vacío de contenido. Se convierte en un significante apto para ser utilizado con otro sentido» ${ }^{11}$.

Este "otro sentido" coincide con la perspectiva objetiva cuyo máximo representante teórico es E. Coseriu. Para él -y para los lingüistas posteriores, que (quiéranlo o no) han de tomarlo como referencia- la norma es lo norma/ ${ }^{12}$, lo que se dice de acuerdo con la tradición en una comunidad determinada: decimos lo que se dice como vamos a ver la película de la que todo el mundo habla, o vestimos lo que "se

7. SECO, M.; O. ANDRÉS y G. RAMOS, Diccionario del español actual (2 vols.). Madrid, Aguilar, 1999.

8. Dos buenos resúmenes de la trayectoria histórica que han seguido estas dos perspectivas pueden verse en los trabajos de ZAMORA SALAMANCA (1985) y HERNÁNDEZ, C. (1993).

9. NARBONA, A. (2001), p. 1.

10. DEMONTE, V. (2001b).

11. GUTIÉRREZ, S. (2001), p. 4.

12. Resulta esclarecedor y muy fructífero al respecto percatarse de que el adjetivo normal es un derivado del sustantivo norma. 
lleva" ("Llévese esto, que lo vendo mucho", nos alegan en cualquier comercio). Desarrollemos esta concepción objetiva.

Dado que se entiende por correcto lo "que se ajusta a la norma", Coseriu ${ }^{13}$ lo define como 'lo que se dice allí donde se dice y cabe decirlo', mientras que deviene incorrecto 'lo que no se dice allí ni cabe decirlo'. Cuenta J. L. Conde ${ }^{14}$ que en su infancia los niños de los barrios bajos se reían de él, un niño bien, cuando decía "se me" y no "me se". En La Rioja, y en otras zonas ${ }^{15}$, se usa mucho coloquialmente canilla con el significado de 'grifo'. Pues bien, una muy conocida logroñesa, tras escoger el menú en un restaurante madrileño, recibió la habitual pregunta del camarero: $«-i Y$ para beber? -Agua, le contestó. - ¿De qué marca? -iBah! De la canilla mismo. Al cabo de un buen rato, el camarero volvió para decirle: ¿Le importa que el agua sea de otra marca; es que de "La Canilla" no nos queda» ${ }^{16}$. Si nuestra logroñesa se hubiera encontrado en un restaurante de Puerto Rico y hubiera pedido agua "de la pluma", seguro que el camarero no hubiera perdido el tiempo buscando marcas inexistentes. Cuando hace tres años tuve el placer de estar allí, al presidente de la Universidad Católica de Ponce le comenté que me había Ilamado la atención algo sobre los mojones de las carreteras. Muy amablemente me recomendó que tuviera cuidado con la palabra mojón porque en Puerto Rico significa 'montoncito de heces humanas'.

El uso, por lo tanto, es el gran criterio de corrección, aunque se oponga a lo oficial, que, si persiste, acaba reconociéndolo. Bernárde $z^{17}$ compara, sugerentemente, la norma lingüística con lo que ocurre con determinados jardines: por no bordearlos hay quien toma la iniciativa de cruzarlos; al principio, éste es recriminado, pero otros siguen su ejemplo hasta terminar pisándolos los mismos recriminadores; al final, el propio Ayuntamiento se ve obligado a construir una senda oficial.

No obstante, Coseriu ${ }^{18}$ nos advierte de que también hay que considerar correcto, aunque no sea usual, lo que está bien formado de acuerdo con el sistema de la lengua, ya que el sistema constituye un conjunto de posibilidades (gracias al sistema la lengua es futuro, además de pasado y presente) y la norma contiene el sistema. Por ejemplo, siguiendo el modelo de aterrizar o de alunizar, bien podemos referirnos con ajovizar a 'posarse en el planeta Júpiter'; si existe un alcoholímetro, ipor qué no un nicotinímetro? Hace unos meses oí en la radio este anuncio, interesantísimo al respecto: Una mujer le dice a un hombre: -Si tienes problemas de estreñimiento, Agiolax ayuda a desestreñir. -i"Desestreñir"?, dice él [paradigma claro del conservador comentado]. Esa palabra no existe. A lo que replica ella, práctica e inteligente: -Pues no existirá la palabra; pero lo que hace Agiolax es desestreñir; y apostilla: ¿cómo lo dirías tú, si no? Una pregunta final, por cierto, bien perspicaz y oportuna: dado que se trata de una realidad tabú, nos solemos referir a ella con eufemismos, y así decimos que los laxantes

13. COSERIU, E. (1992a), pp. 14-15.

14. CONDE, J. L. (2001), p. 101.

15. Argentina, Bolivia, Paraguay y Uruguay, según el $D R A E$, ac. 8.

16. GONZÁLEZ, F. y J. J. MANGADO, En román paladino. Logroño, IER-Diario La Rioja-Santos Ochoa, 1999, art. 185.

17. BERNÁRDEZ, E. (1999), pp. 57-58.

18. COSERIU, E. (1992a), p. 15. 
nos ayudan a ir al baño, a ir bien del cuerpo, a "eso" o, en norma más formal y un tanto pedante, que facilitan el tránsito intestinal. ¿Es correcto usar desestreñir 'evitar el estreñimiento', un verbo que no aparece en los diccionarios? Naturalmente que sí, tanto como emplear descongestionar 'evitar la congestión', que sí figura en ellos. Y, además, como éste, desestreñir constituye un vocablo útil, objetivo y sin estigma.

Pero (como cualquier otra norma social: por eso se llega a hablar de "tiranía de la moda") libertad individual no es precisamente lo que brinda la norma lingüística. Ésta se impone al individuo limitando sus opciones expresivas. El sistema le ofrece posibilidades que la norma restringe; le abre puertas que la norma cierra. Cuando el hablante no conoce la norma, se guía por el sistema, pero no siempre da con lo normal-usual: eso les ocurre, por ejemplo, a los niños cuando dicen sabo, cabo, hacido, decido o ponido, y también a los no tan niños cuando profieren andé, conducí, bendiciera, satisfació...

La norma así entendida es tan poderosa que incluso las alternativas canónicas u oficiales no siempre cuajan: mercadotecnia, elite, casete, tique o güisqui, por ejemplo, a pesar de los esfuerzos de la Real Academia por que arraiguen, no acaban de lograr el favor de los hispanohablantes, los cuales en general prefieren marketing, élite, cassette, ticket o whisky. Y a veces, en cambio, triunfan expresiones estrictamente incongruentes: No quiero nada en español, contra toda lógica, no niega Nada quiero, sino que equivale a este enunciado; Se lo retendremos hasta que no pague no implica la voluntad de dar a entender que alguien está pagando de manera continua, aunque esto es lo que objetivamente manifiesta ${ }^{19}$; Se lo dije una vez y no se lo volveré a repetir no quiere expresar disposición de conceder una segunda oportunidad, precisamente, pero eso supone, puesto que para 'volver a repetir' resulta imprescindible 'haber repetido' previamente ${ }^{20}$.

Subrayemos: objetivamente, pues, la norma consiste en cómo se dice, no en cómo se debe decir, y le cuadran los conceptos normal/ anormal [o usual/ inusual], no los de correcto / incorrecto (entendidos éstos en sentido prescriptivo) ${ }^{21}$. Puesto que la norma así entendida se fundamenta en el uso y los usos son múltiples, no habrá una sola norma idiomática, sino muchas, tantas como entidades diatópicas, diastráticas y diafásicas existen. Y nuestra lengua siempre ha contado con una gran pluralidad de normas: geográficas, sociales y particulares.

\section{LO EJEMPLAR}

Dada la existencia de una amplia pluralidad de normas, para salvaguardar la unidad de la lengua compartida y facilitar la intercomunicación entre los realizadores

19. Es decir, según lo que oímos en el uso diario de nuestro idioma, en Ya tenemos arreglado el televisor, pero se lo retendremos hasta que no pague, por ejemplo, se lo retendremos hasta que no pague equivale a se lo retendremos hasta que pague.

20. El uso ilógico e impropio del verbo repetir es una de las peculiaridades idiomáticas más en boga del español. Resulta raro encontrar a alguien que, al proferir Se lo repetí tres veces, quiera expresar lo que lógica y propiamente eso significa: 'se lo dije cuatro veces'; la inmensa mayoría pretende comunicar con ese enunciado 'se lo dije tres veces'.

21. COSERIU, E. (1967), p. 90. 
de las diversas normas se necesita una norma comodín, una "supernorma" o norma "supercorrecta" (en el sentido objetivo de correcto), una especie de "segunda lengua" común dentro y por encima de la lengua común, es decir, una lengua sintópica, sinstrática y sinfásica que funcione como koiné.

A este tipo de norma comodín se le han dado múltiples nombres: "lengua, o norma, estándar", "norma culta", "lengua ejemplar", "norma, o lengua, neutra", "supernorma", "lengua consagrada", "norma ideal", "ideal de lengua", "variedad formal" ...22 Siguiendo la tendencia mayoritaria en los últimos años, me referiré a ella aquí como lengua, o norma, estándar y, respetando la terminología de Coseriu, usaré ejemplar para su versión adjetiva, de manera que correcto o normal se corresponderán con 'norma', con cualquier norma, y ejemplar, con la 'norma estándar'.

Inspirándome en la bibliografía al respecto, entiendo la "lengua estándar" como una norma ideal, una abstracción, en el plano nacional e internacional, elegida para su empleo, por encima de la variedad regional y sociocultural, para las tareas comunes. Analicemos estos cuatro elementos destacados.

1. La lengua estándar constituye una norma ideal; es una abstracción, una "abstracción conformada a partir de un amplio conjunto de variedades lingüísticas, diatópicas, diastráticas y diafásicas" (precisa C. Hernández²3). Se caracteriza por su "intelectualización"; es decir, por su capacidad de expresar riqueza de matices (en opinión de Havránek y Mathesius recogida por este profesor ${ }^{24}$ ). Por eso consiste en una lengua culta (con elementos propios como cuyo [frente al que su coloquial], obsequiar, imputar 'achacar', inexorable, extraer, extirpar, proyectar [una película]...), que además quiere parecerlo, pues manifiesta mayor conciencia de lengua estándar. Por esa razón muchos hablantes incurren en abusos (los monótonos finalizar, iniciar, realizar... desbancadores de acabar, empezar, hacer...), en "lenguajitis", 'preferencia por las expresiones más largas' (finalización, recepcionar, influenciar... frente a fin, recibir, influir...), o ultracorrecciones (espúreo, périto, líbido...).

Presenta mayor homogeneidad en su versión escrita que en la hablada: la escritura se erige en factor de extraordinaria fuerza al respecto, como resalta Lope Blanch ${ }^{25}$. Pero menos en la literatura; por eso (como advierte C. Hernández) es preocupante la opinión de algunos lingüistas, entre ellos los de la Escuela de Praga (sobre todo, Havránek y Mathesius), de que la lengua estándar coincidiría con la literaria.

2. Esa "norma ideal" es elegida por los hablantes de la lengua común: no puede imponerse de manera vertical, sino que se configura horizontalmente. Ni los lingüistas crean las lenguas ni los políticos pueden aclimatarlas por decreto: "Grammatici -escribió Séneca- custodes sunt, non auctores linguae"26; y Chomsky, en

22. Cf., sobre todo, al respecto el trabajo de ZAMORA SALAMANCA (1985).

23. HERNÁNDEZ, C. (2001), p. 1.

24. Ibíd., p. 4.

25. LOPE BLANCH, J. M. (2001), pp. 6-7.

26. Citado por GUTIÉRREZ, S. (2001), p. 3. 
unas declaraciones recientes a la prensa, advertía de que "la lengua no es de los políticos ni, mucho menos, de los filólogos". La función de la Real Academia al respecto, por ejemplo, no radica, como creen muchas personas, en imponer la presunta única lengua correcta ${ }^{27}$, sino en iluminar el camino que se considera más acorde con la identidad de la lengua histórica; si ese camino no se sigue mayoritariamente, la Real Academia ha de ser notaria de la existencia del nuevo.

Los criterios configuradores de la lengua estándar, como explica Martín Zorraquino ${ }^{28}$, se manifiestan diversos y la censura de sus novedades admite objeciones: ¿por qué no aceptar -se pregunta esta profesora- nuevas formaciones léxicas, como, por ejemplo, papable, alcaldable...?; a menudo se reprueban los cambios no porque produzcan desajustes en el sistema, sino sólo por respeto al uso vigente o tradicional: como el empleo de la forma verbal en -ra con valor de pasado de indicativo (Todavía recuerdan los aficionados el gol que metiera aquí Ronaldo cuando era jugador del Barcelona), o el de incautar (que está siguiendo un proceso paralelo al de desayunarse > desayunar, al que luego me referiré).

Caben posturas varias y, por lo tanto, conviene (se impone) la flexibilidad. A propósito de cambios y novedades, resulta fundamental resaltar que, como señala $\operatorname{Coseriu}^{29}$, la lengua estándar no está entera y definitivamente constituida: en parte está constituida y en parte en vías de constitución; es decir, consta de una parte más o menos fijada y de todo un mundo de posibilidades que pueden ir actualizándose. Se caracteriza por la "estabilidad flexible" que le asignan Mathesius y Havránek y que recoge $C$. Hernández ${ }^{30}$. Se trata, en expresión afortunada de Emilio Lorenzo, de una "lengua en ebullición". Y es que las lenguas no son érgon, sino enérgeia; no son 'producto' o 'resultado', sino 'actividad' constante. En una estrofa del célebre Romance del Duero Gerardo Diego escribe con claras resonancias heraclitianas:

Quién pudiera como tú,

a la vez quieto y en marcha,

cantar siempre el mismo verso,

pero con distinta agua.

Así es la lengua: a la vez quieta y en marcha, en tensión permanente entre una fuerza centrípeta conservadora y otra centrífuga innovadora; canta siempre el mismo verso, es decir, resulta siempre igual de apta para la comunicación necesaria en un molde semejante; consiste siempre en el mismo río, pero con distinta agua, ya que sus elementos se renuevan constantemente.

Hasta 1984 no registra el $D R A E$, por ejemplo, el verbo desayunar; en las ediciones anteriores sólo figuraba desayunarse (intransitivo y pronominal). Está claro

27. "Que una palabra figure o no en el famoso diccionario académico no quiere decir nada: ni una palabra es "mejor" por figurar en él, ni "peor" (mucho menos "inexistente") porque no se haya recogido en esos famosos volúmenes» (BERNÁRDEZ, E., 1999, p. 49.

28. MARTÍN ZORRAQUINO, M.를. (2001), p. 11.

29. COSERIU, E. (1990), pp. 60 y, sobre todo, 67.

30. HERNÁNDEZ, C. (2001), p. 4. 
que hoy, al menos en España, el tradicional "desayunarse con café con leche y galletas" ha quedado claramente inusual frente al habitual "desayunar café con leche y galletas". El adjetivo lúdicro todavía figura, para sorpresa de muchos, en el $D R A E$ vigente; pero más sorprendidos se verían si supieran que esa voz ha pasado en pocos años de ser la única versión oficial a arcaísmo práctico: efectivamente, en el DRAE de 1970 no aparece lúdico, sino sólo lúdicro; en el de 1984 se recogen ambos, si bien lúdicro constituye la forma recomendada; en el de 1992 y en el actual de 2001 se registran los dos, pero lúdico pasa a ser ya la versión recomendada ${ }^{31}$. No parece arriesgado vaticinar la próxima desaparición de lúdicro de los diccionarios de uso. Y pensemos en la incesante introducción de neologismos, como cederrón, set, rally, vasectomía, riñonera, dosier, flipar, parapente, seropositivo, karaoke, bluyines... o desestreñir.

3. Moreno de $\mathrm{Alba}^{32}$, refiriéndose al léxico de los diferentes países de la América hispana, aduce la siguiente cita de Rufino José Cuervo (en su prólogo al poema Nastasio de Soto y Calvo): "Hoy sin dificultad y con deleite leemos las obras de los escritores americanos sobre historia, literatura, filosofía; pero en Ilegando a lo familiar o lo local, necesitamos glosarios". Una lengua histórica es un conjunto complejo de dialectos, niveles y estilos (afirma Coseriu ${ }^{33}$ ). La lengua estándar no constituye, ni mucho menos, el único modo de hablar, ni siquiera la lengua común (aunque aspire a ello). Más aún, la deseable atención a la lengua estándar no debe suponer desprecio de las otras variedades y registros (ni siquiera del tan denostado espanglish), sino tolerancia, flexibilidad y respeto recíproco.

No hay que emprender una cruzada contra todo lo que se oponga a la presuntamente "única lengua correcta" (que ya hemos visto que no existe). Determinados usos (como el voseo, el laísmo... o la pronunciación "-ao" por -ado) no son vicios, sino rasgos "neutros", legítimos en su ámbito aunque no pertenezcan a la lengua ejemplar. Los hablantes que deseen hablar con corrección (nos advierte Coseriu $^{34}$ ) no han de ser "monolingües" usando exclusivamente la lengua ejemplar, sino "plurilingües": han de hablar de forma diferenciada según las circunstancias y los niveles sin mezclarlos. "Eso sí que es hablar bien, saber adaptar nuestra lengua al contexto, también a nuestro interlocutor ${ }^{\prime \prime 35}$.

La lengua estándar no tiene como misión sustituir en toda ocasión las variedades regionales y socioculturales destruyendo así un patrimonio lingüístico y cultural indudable, sino constituirse en marco de referencia donde confluyen

31. Ejemplo tomado de GÓMEZ TORREGO, L., "Cambios normativos en el español actual", en V. DEMONTE y S. GUTIÉRREZ ORDÓÑ̃EZ, El buen uso de la lengua española. Bur-

gos, Caja de Burgos, 2001, pp. 27-28.

32. MORENO DE ALBA, J. (2001), p. 2.

33. COSERIU, E. (1990), p. 56.

34. COSERIU, E. (1990), p. 69: «No cabe, en efecto, aspirar a la nivelación radical "para arri-

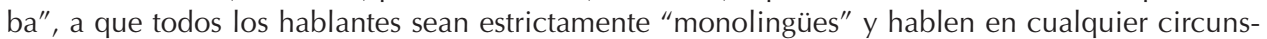
tancia sólo la lengua ejemplar (poniéndose incluso ridículos), sino, más bien, a que un número cada vez mayor de hablantes sean "plurilingües" dentro de su lengua histórica y hablen en forma diferenciada, de acuerdo con las circunstancias y los niveles del hablar».

35. BERNÁRDEZ, E. (1999), p. 49. 
todas, estar disponible por encima de ellas para determinadas tareas comunes. "El estándar no es la consagración del hablar bien, es simplemente un acuerdo social más o menos tácito que permite entenderse perfectamente a personas de distintos orígenes nacionales, regionales y sociales" ${ }^{\prime \prime 6}$. Una vez más, no se trata de restar, sino de sumar.

4. Esas tareas o situaciones comunes en las que se utiliza la lengua estándar las clasifica Wagner ${ }^{37}$ en los siguientes grupos: diálogos: conversaciones con desconocidos, mesas redondas, congresos, seminarios...; exposiciones: conferencias, clases...; difusión periodística: prensa, radio, televisión...; discursos: políticos, religiosos, sociales, judiciales...; informes: científicos, administrativos, ensayos...; publicidad: comercial, ideológica... Es decir, como resume Martín Zorraquino $^{38}$, usaremos la lengua estándar cuando la comunicación deja de ser estrictamente privada. Entonces se siente como patrimonio cultural de todos, y esas funciones comunes oficiales, o simplemente públicas, le confieren un rango superior y prestigio. Por eso, en esas situaciones todo hablante culto renuncia generalmente a sus peculiaridades locales.

\subsection{Lo ejemplar hispánico o el español estándar}

Coseriu puntualiza (ya lo he citado antes) que "una lengua histórica de cierta entidad no es nunca primariamente unitaria", sino "un conjunto complejo de dialectos, niveles y estilos". Pues bien, si toda lengua histórica "de cierta entidad" necesita, como tal, una norma estándar o ejemplar, esa necesidad se muestra especialmente evidente en el caso del español, que siempre se ha caracterizado por una gran pluralidad de normas; una lengua en imparable expansión que hablan más de cuatrocientos millones de personas de muy diferente condición geográfica, cultural y social, y que es la oficial de veinte países.

Últimamente la norma panhispánica centra el interés y la preocupación de muchos lingüistas y, particularmente, de los académicos. Se trata de reforzar una koiné hispánica. Importa subrayar que el español no es patrimonio exclusivo de España; hace siglos que no lo es, y mucho menos hoy que nuestro país suma menos del diez por ciento del total de hispanohablantes del mundo. Contar con el español de América para fijar la ejemplaridad hispánica no resulta, pues, sólo justo, sino esencial, ineludible. Además, aspirar a una ejemplaridad panhispánica no supone una empresa descabellada: la bibliografía seria al respecto coincide en destacar que el español culto de América, pese a su vastedad, no amenaza la unidad idiomática ya que ni se aleja del de España ni se fragmenta a su vez: las dos ramas se han venido aproximando e identificando cada vez más.

Como afirma Narbona ${ }^{39}$, "el centripetismo no es de intensidad menor que el dinamismo divergente". En una ponencia interesante de título provocador ("En

36. Ibíd., p. 48.

37. HERNÁNDEZ, C. (2001), p. 9.

38. MARTÍN ZORRAQUINO, M.․ㅡ A. (2001), p. 4.

39. NARBONA, A. (2001), p. 8. 
defensa del español mal hablado...") el periodista Jorge Ramos, acostumbrado a bregar a diario con el idioma en una televisión hispana estadounidense, asegura: "Son totalmente infundados los temores de que el español está siendo invadido o que corre el riesgo de desaparecer [...]. Ante las nuevas convergencias en las comunicaciones, la globalización, los embates de la Internet y el espanglish, el español no puede más que fortalecerse" ${ }^{\prime 40}$. Lope Blanch manifiesta que (omitiendo las diferencias léxicas) las discrepancias de carácter gramatical (incluyendo aquí lo fonológico) entre las normas cultas de los diversos países hispanohablantes "son pocas, muy pocas", en "número posiblemente inferior al de los dedos del cuerpo humano", frente a los "miles y miles de formas y de construcciones" comunes ${ }^{41}$.

Hay que tener en cuenta que la lengua estándar unificadora panhispánica a la que, loablemente, se tiende ha de constituir una sola voz, pero de tonalidad diversa, o sea, una norma que, en palabras de César Hernández, "respet[e] todas las variedades y peculiaridades" arraigadas ${ }^{42}$ o que, como matiza Lope Blanch, "reúna y compendie los hechos lingüísticos propios y comunes de todas las normas cultas nacionales" ${ }^{43}$. Ha de ser, en palabras de Coseriu, ya que cada país tiene su propia ejemplaridad, una superejemplaridad "dinámica, flexible y oportuna".

Ahora bien, ¿cómo establecer la norma panhispánica en los casos en que haya divergencias entre las diversas normas ejemplares nacionales? Lope Blanch ${ }^{44}$ ve dos situaciones posibles, a cada una de las cuales aporta una solución digna de tenerse en cuenta: 1) Que la forma propia de una de esas normas sea gramatical o socioculturalmente menos justificable que la otra. En tal caso, no debería haber conflicto, afirma: la forma divergente menos justificable no se considerará ejemplar panhispánica, aunque sea válida en su ejemplaridad nacional. Y aduce, entre otros, los ejemplos del rehilamiento ensordecido de la palatal central ${ }^{45}$, propio sólo de las hablas cultas del Río de la Plata (en el resto de las normas hispánicas, se pronuncia sin rehilamiento), y la eliminación de /d/ en la terminación -ado aceptada por la norma culta castellana y de otras regiones (soldao, cansao...), pero rechazada mayoritariamente. Ambos fenómenos no han de considerarse ejemplares panhispánicos. 2) Que ambas formas sean igualmente justificables y estén respaldadas ambas por una norma nacional de prestigio. En esta situación, habrá que aceptar las dos formas divergentes como propias de la ejemplaridad panhispánica. Aporta, entre otros, los ejemplos del seseo y las alternancias canté / he cantado o vosotros / ustedes [a los que podríamos añadir, verbigracia, la reciente norma ortográfica según la cual pueden tildarse o no determinadas palabras (bisílabas con hiato, monosílabas con diptongo), como guión o guion, truhán o truhan, riáis o riais...]. Ambos elementos de cada alternancia han de considerarse ejemplares panhispánicos por razones históricas o de uso extendido en las ejemplaridades nacionales.

40. RAMOS, J. (2001), p. 12.

41. LOPE BLANCH, J. M. (2001), pp. 4-5.

42. HERNÁNDEZ, C. (2001), p. 8.

43. LOPE BLANCH, J. M. (2001), p. 3.

44. Ibíd., pp. 5-6.

45. Esa ye casi ese que oímos en las televisiones de España a los futbolistas argentinos, por ejemplo, cuando pronuncian yo, rayo, vaya...y también caballo, calle, llover... 
En cualquier caso, hay que resaltar que la lengua estándar panhispánica constituye una norma ideal; no será la norma real de ninguna de las hablas hispánicas (nos recuerda Lope Blanch ${ }^{46}$. El hablante, por lo tanto $-y$ esto es trascendental-, no la adquiere en el aprendizaje espontáneo natural de la lengua como adquiere las otras variedades de su entorno ${ }^{47}$. En consecuencia, ha de estudiarla. Y, en correspondencia, como afirma C. Hernández, hay que enseñar "la lengua culta estándar" y "no sólo se ha de enseñar esa norma, sino que se debe enseñar en esa norma culta" ${ }^{48}$. He aquí la justificación elemental de la lingüística normativa. Y no cabe escudarse en la provisionalidad de las normas para esquivarla: "la norma -escribe V. Demonte-, reflejo de variaciones posibles y no accidentales, es una parte esencial de la gramática descriptiva y de la gramática teórica", porque "permite afinar mejor cuáles son las reglas que subyacen a las construcciones de nuestra lengua" y "enriquece la reflexión teórica y, desde luego, conduce a una descripción mucho más afinada de los fenómenos en liza" ${ }^{\prime 4}$.

En definitiva, se trata, por ejemplo, de que, mediante el conocimiento de la lengua estándar o ejemplar panhispánica, un argentino, un chileno, un mexicano o un puertoriqueño puedan entender sin problemas lo que se escribe en el diario "La Rioja", y un riojano pueda leer sin dificultades "La Nación", "El Mercurio", "Excélsior" o "El nuevo día".

\section{LO "RECTO"}

Hasta ahora hemos deslindado los conceptos de 'lo normal o usual' y 'lo ejemplar', subsumidos (y, por lo general, confundidos) en el empleo corriente del término correcto. Pero no son ésos los únicos conceptos que encierra ese término ambiguo, aunque sí los de mayor trascendencia teórica. En mi opinión, a estos dos conviene añadir otro para evitar confusiones y dirimir fácilmente controversias idiomáticas.

Cuando se nos pregunta, por ejemplo, si es correcto escribir "Rocíito" o decir "pupurri", "dentrífico", "ese agua", "un traspiés", "veintiún semanas", "detrás mío", "cesar al entrenador", "el niño que su padre es albañil" o "yo soy de los que pienso"; o cuál es la versión correcta, o la más correcta, de determinadas alternancias (¿extravertido o extrovertido?, ¿informar que o informar de que?, ¿repantigarse o repantingarse?, ¿élite o elite?, ¿riojanidad o riojaneidad?...), nuestro interlocutor no

46. LOPE BLANCH, J. M. (2001), p. 3.

47. En el español, por ejemplo, que yo aprendí en mi niñez, las 'lagartijas' eran ardachillas, los 'cerdos' marranchos, los 'grifos' canillas, los 'corderos de leche' ternegones, las 'tapias' paletillas... Y así seguía usando en mi pueblo esas palabras, aun después de conocer por la escuela la existencia "superior" de lagartija, cerdo, grifo..., simplemente porque allí así se usaban. Fue después, al abandonar el pueblo, cuando evitaba referirme a la 'lagartija', por ejemplo, con ardachiIla, en favor de lagartija, para facilitar la comunicación, y de paso eludir mofas, como otros renunciaban a zarandilla, sargandilla, zarceta, sargantana..., también en favor de lagartija, por los mismos motivos. Así intuí que había normas particulares (las de ardachilla, zarandilla, sargandiIla, zarceta, sargantana...) y una supernorma o norma estándar (la de lagartija).

48. HERNÁNDEZ, C. (2001), p. 9.

49. DEMONTE, V. (2001b), p. 104. 
quiere conocer (o, al menos, no prioritariamente) la versión habitual y en qué grado (es decir, no nos pregunta por lo 'usual' o por lo 'ejemplar'), sino cuál se identifica con la forma construida de acuerdo con los cánones de nuestro sistema lingüístico. Nosotros así lo entendemos y, aunque con las oportunas matizaciones (ahora sí) sobre el uso y la norma estándar, le explicamos que las respectivas versiones canónicas son: "Rociito", "popurrí", "dentífrico", "esa agua", "un traspié", "veintiuna semanas", "detrás de mî", "destituir al entrenador", "el niño cuyo padre es albañil", "yo soy de los que piensan", "extravertido", "informar de que", "repantigarse", "elite" y "riojanidad".

A este concepto que, humildemente, me permito aportar aquí podríamos darle el nombre de lo recto, en el sentido de su étimo latino RECTUM, participio pasivo del verbo REGERE en sus acepciones de 'dirigir', 'guiar', 'fijar', 'delimitar'; nombre que lo distingue explícitamente de lo correcto, de CORRIGERE (CO + REGERE) 'enmendar', 'reformar', 'rectificar' (etimológicamente, 'codirigir', 'coguiar', 'cofijar', 'codelimi$\left.\operatorname{tar}^{\prime}\right)$. De esta manera podemos entender por unidades lingüísticas rectas las canónicas, las verticalmente configuradas y preestablecidas; mientras que correctas consideraremos, en plena sintonía con la concepción coseriana explicada, las coestablecidas, las cofijadas horizontalmente, sean rectas o no. Las primeras son las dadas; las segundas, las mantenidas, reformadas, adoptadas o creadas por la comunidad de hablantes.

Para precisar más el concepto, podemos distinguir, dentro de lo recto, tres tipos de elementos: 1) los primigenios, es decir, los originales y etimológicos; 2) los canónicamente evolucionados, o sea, los que se han transformado de acuerdo con lo esperable según las tendencias o leyes de la evolución lingüística; 3) los canónicamente creados. La tríada directo (forma etimológica) / derecho (forma con evolución normal del grupo -KT-) / dirigido (participio analógico regular) ejemplifica bien, respectivamente, los tres subconceptos.

Las formas rectas, por ser normales (de existencia o construcción normal, acorde con los cánones), son siempre correctas: en acto (las tres que acabo de aducir, por ejemplo) o en potencia (desestreñir, verbigracia, por el momento, o ustedear); aunque no siempre alcancen el estatus de ejemplares: decimoprimero y decimosegundo, por ejemplo, son cada vez más usuales, pero inaceptados sustitutos, hoy por hoy, de undécimo y duodécimo en la lengua estándar. Una realización lingüística puede alcanzar, pues, la corrección por dos vías de normalidad: por su uso (esprínter, por ejemplo, forma no recta, pero sí usual, en español) o por su configuración regular (esprintador, verbigracia, forma inusual, aunque recta).

A menudo las formas rectas, por el dinamismo propio de la lengua (enérgeia), experimentan con el uso una serie de alteraciones debidas a múltiples fenómenos (analogía, cruce, ultracorrección, asimilación, disimilación, diversas fobias y filias...): dijistes, cohexión, espúreo, minisco, fustrar, tangana o recepcionar constituyen algunas muestras de ello muy actuales.

Si triunfan, esas formas alteradas pasan a ser correctas: eso les ha ocurrido, como a la senda del jardín del ejemplo de Bernárdez, a repantingar, cotidianeidad, extrovertido, adecúa, garrulo... (frente a sus versiones rectas, hoy por hoy todavía las ejemplares, repantigar, cotidianidad, extravertido, adecua, gárrulo...); incluso ejem- 
plares (como murciélago, aguinaldo, élite...) ${ }^{50}$, y hasta únicas (como estrella, avispa, propio, reina, boda... $)^{51}$. Un caso emblemático al respecto constituyen los sintagmas conmigo, contigo y consigo: se trata de formas doblemente desviadas o no rectas (tanto desde el punto de vista etimológico, como desde el analógico, muestran redundancia $)^{52} y$, sin embargo, representan las únicas formas ejemplares, mientras que sus versiones analógicas con mí, con ti, con sí, a pesar de ser rectas, son rechazadas en la lengua estándar por considerarlas propias de ámbitos vulgares. Está claro que en la norma lingüística, como en cualquier otra norma humana, no importa tanto cómo son las cosas cuanto cómo nos parecen.

\section{CONCLUSIONES}

1) Hay que tomar conciencia de la polisemia del término (in)correcto y, consecuentemente, distinguir los conceptos diferentes que se confunden por encontrarse cofundidos en él.

2) En el uso del idioma lo 'correcto' se identifica con lo 'normal'.

3) Una realización idiomática ha de considerarse normal, y por lo tanto correcta, si está construida de acuerdo con los cánones del sistema de la lengua correspondiente; o sea, si es recta.

4) Una realización idiomática es normal, y por lo tanto correcta, si, recta o no, se manifiesta usual en la comunidad lingüística donde se emite.

5) Puesto que las comunidades lingüísticas presentan diferencias evidentes (geográficas, históricas, sociales, culturales...), se necesita una "supernorma" o norma estándar, la ejemplar, que, usual en determinadas circunstancias dentro de la misma lengua, facilite correctamente la comunicación intercomunitaria.

6) Entendemos por español estándar o ejemplar la supravariedad de prestigio adoptada por convención, en el plano nacional y en el internacional, tenida como modelo de uso público u oficial.

7) Dado que la variedad lingüística que se adquiere de forma natural no es la intercomunitaria, sino la intracomunitaria, se hace imprescindible estudiar la norma ejemplar para, conociéndola, usarla adecuadamente y fijarla.

8) Tal necesidad resulta más acuciante aún, si cabe, en el caso del español, una lengua hablada por más de 400 millones de personas en el mundo integradas en comunidades muy diferentes.

50. Sus versiones rectas etimológicas (murciégalo, aguilando, elite) no han gozado del favor general o se consideran vulgares o rurales.

51. Formas que, tomando como referencia su étimo (respectivamente, STELLA, VESPA, PROPRIU, REGINA, VOTA), no son rectas, puesto que presentan anomalías: injerencia de un fonema $(-r$ - en estrella, a- en avispa), desaparición de un fonema (-r-en propio), desplazamiento acentual (reina), alteración ortográfica (boda). Sus correspondientes versiones rectas serían estela, vispa, proprio, reína, voda.

52. Cf. mi capítulo “¿Por qué conmigo y no con m??, en el cit. En román paladino, art. 71. 
9) La lingüística normativa, la encargada del estudio de la lengua estándar, cobra así razón de ser y una justificación científica que le abre incluso las puertas en la Universidad a la docencia y a la investigación.

10) En consecuencia, la lingüística normativa del español ha de formar parte de los currículos académicos de los países hispánicos (aunque progresivamente, en todos los niveles educativos), y en todos ellos ha de enseñarse cualquier materia en la variedad ejemplar o estándar panhispánica.

\section{Bibliografía}

ALARCOS LLORACH, E. (1990), Las gramáticas de la Academia. Logroño, Gobierno de La Rioja (Lecciones de lingüística y didáctica del español, 4).

ALBA OVALLE, O. (2001), "El español estándar desde la perspectiva dominicana", en II Congreso Internacional de la Lengua Española, Valladolid, http://cvc.cervantes.es/obref/congresos/valladolid/ponencias/unidad_diversidad_del_espanol/1_la_norma_hispanica/alba_o.htm (7 pp.).

ALONSO, D. (1964), "Para evitar la diversificación de nuestra lengua", en Presente y futuro de la lengua española, II, Madrid, Ediciones de Cultura Hispánica, pp. 259-268.

ALVAR, M. (1982), "La norma lingüística", en La lengua como libertad y otros estudios, Madrid, Ediciones Cultura Hispánica del Instituto de Cooperación Iberoamericana.

- (1990), "La lengua, los dialectos y la cuestión de prestigio", en F. MORENO (recop.), Estudios sobre variación lingüística, Alcalá de Henares, Universidad de Alcalá, pp. 13-26.

ÁLVAREZ MARTíNEZ, M.․ㅗ. A. (1989), "Las gramáticas y las normas", en RSEL, 19, pp. 435-442.

ÁVILA R. (2001), "Los medios de comunicación masiva y el español internacional", en I/ Congreso Internacional de la Lengua Española, Valladolid, http://cvc.cervantes.es/obref/congresos/valladolid/ponencias/unidad_diversidad_del_espanol/1_la_norma_hispanica/avila_r.htm.

BERNÁRDEZ, E. (1999), ¿Qué son las lenguas? Madrid, Alianza.

BLECUA, J. M. (2001), "Unidad, variedad y enseñanza", en II Congreso Internacional de la Lengua Española, Valladolid, http://cvc.cervantes.es/obref/congresos/ valladolid/ponencias/unidad_diversidad_del_espanol/1_la_norma_hispanica/ble cua_j.htm (7 pp.).

CARO, M. A. (1980), Obras (tomo 3: Estudios lingüísticos, gramaticales y filológiCos), Bogotá, Instituto Caro y Cuervo.

CONDE, J. L. (2001), El segundo amo del lenguaje. Madrid, Debate.

COSERIU, E. (1967), "Sistema, norma y habla", en Teoría del lenguaje y lingüística general. Madrid, Gredos, pp. 11-113.

- (1981), "Los conceptos de 'dialecto', 'nivel' y 'estilo de lengua' y el sentido propio de la dialectología", en LEA, III/1, pp. 1-32. 
- (1990), "El español de América y la unidad del idioma", en I Simposio de Filología Iberoamericana (Sevilla, 26 al 30 de marzo de 1990), Zaragoza, Pórtico, pp. 43-75.

— [1992a], "La corrección idiomática" [original mecanografiado].

- (1992b), Competencia lingüística (Elementos de la teoría del hablar). Madrid, Gredos.

DEMONTE, V. (2001a), "El español estándar (ab)suelto. Algunos ejemplos del léxico y la gramática", en II Congreso Internacional de la Lengua Española, Valladolid, http://cvc.cervantes.es/obref/congresos/valladolid/ponencias/unidad_diversidad_del_espanol/1_la_norma_hispanica/demonte_v.htm (23 pp.).

DEMONTE, V. (2001b), "La gramática descriptiva y la necesidad de la gramática", en GÓMEZ TORREGO, L., S. GUTIÉRREZ ORDÓÑEZ y , El buen uso de la lengua española. Burgos, Caja de Burgos, pp. 67-108.

GALLARDO, A. (1978), "Hacia una teoría del idioma estándar", en RLA, 16, pp. 85119.

- (1983), "Planificación lingüística y ejemplaridad literaria", en $R L A, 21$, pp. 107116.

GÓMEZ ASENCIO, J. (2001), "Gramática para americanos, gramática para todos", en II Congreso Internacional de la Lengua Española, Valladolid, http://cvc.cervantes.es/obref/congresos/valladolid/ponencias/unidad_diversidad_del_espanol/2_el_espanol_de_america/gomez_j.htm (20 pp.).

GUTIÉRREZ ORDÓÑ̃EZ, S. (2001), "Perfiles y dimensiones en el concepto de norma (las otras normas)", en II Congreso Internacional de la Lengua Española, Valladolid,http://cvc.cervantes.es/obref/congresos/valladolid/ponencias/unidad_diversidad_del_espanol/1_la_norma_hispanica/gutierrez_s.htm (18 pp.).

HERNÁNDEZ ALONSO, C. (1988), "Normas lingüísticas y estandarización del español", en Letras de Deusto, 40, pp. 47-64.

HERNÁNDEZ ALONSO, C. (1993), "El concepto de norma lingüística en Nebrija: pervivencia y superación", en Anuario de Letras, 31, pp. 183-204.

HERNÁNDEZ ALONSO, C. (2001), “¿Qué norma enseñar?”, en II Congreso Internacional de la Lengua Española, Valladolid, http://cvc.cervantes.es/obref/congresos/valladolid/ponencias/unidad_diversidad_del_espanol/1_la_norma_hispanica /hernandez_c.htm (12 pp.).

LAPESA, R. (1982), "Unidad y variedad de la lengua española", en Cuenta y razón, 8, pp. 21-23.

LARA, L. F. (1976), El concepto de norma en lingüística. México, El Colegio de México.

— (1999), "Normas lingüísticas: pluralidad y jerarquía", en EA, 71, pp. 13-20.

- (2001), "Los diccionarios contemporáneos del español y la normatividad", en II Congreso Internacional de la Lengua Española, Valladolid, http://cvc.cervantes.es/obref/congresos/valladolid/ponencias/unidad_diversidad_del_espanol/2_el _espanol_de_america/lara_l.html.

LLORENTE MALDONADO DE GUEVARA, A. (1986), El lenguaje estándar español y sus variantes. Salamanca, Universidad. 
LOPE BLANCH, J. M.(1972), "El concepto de prestigio y la norma lingüística del español", en Anuario de Letras, X, pp. 29-46.

- (1993), "El ideal de lengua y los países hispanohablantes", en PENNY, R. (ed.), Actas del I Congreso Anglo-Hispano, Madrid, Castalia, vol. 1, pp. 257-274.

- (2001), "La norma lingüística hispánica", en II Congreso Internacional de la Lengua Española, Valladolid, http://cvc.cervantes.es/obref/congresos/valladolid/ ponencias/unidad_diversidad_del_espanol/1_la_norma_hispanica/lope_j.htm (10 pp.).

LÓPEZ GARCíA, Á. (2001), "Unidades y variedades del español", en II Congreso Internacional de la Lengua Española, Valladolid, http://cvc.cervantes.es/obref/ congresos/valladolid/mesas_redondas/lopez_a.htm.

LORENZO, E. (1991), Niveles y registros en el español actual. Logroño, Gobierno de La Rioja (Lecciones de lingüística y didáctica del español, 7).

MARTÍN ZORRAQUINO, M.․ㅡ A. (2001), "El neoespañol y los principios que fundamentan la lengua estándar o consagrada", en II Congreso Internacional de la Lengua Española, Valladolid, http://cvc.cervantes.es/obref/congresos/valladolid/ ponencias/unidad_diversidad_del_espanol/1_la_norma_hispanica/martin_m.htm (22 pp.).

MARTÍN ZORRAQUINO, M.a A. y C. DÍEZ PELEGRÍN (eds.) (2000), ¿Qué español enseñar? Norma y variación lingüísticas en la enseñanza del español a extranjeros. ASELE-Universidad de Zaragoza.

MORENO DE ALBA, J. (2001), "Unidad y diversidad del español: el léxico", en II Congreso Internacional de la Lengua Española, Valladolid, http://cvc.cervantes.es/obref/congresos/valladolid/mesas_redondas/moreno_j.htm (13 pp.).

MOURE, J. L. (2001), "Unidad y variedad en el español de América", en I/ Congreso Internacional de la Lengua Española, Valladolid, http://cvc.cervantes.es/obref/ congresos/valladolid/mesas_redondas/moure_j.htm (11 pp.).

NARBONA, A. (2001), "Movimientos centrífugos y centrípetos en la(s) norma(s) del español", en II Congreso Internacional de la Lengua Española, Valladolid, http://cvc.cervantes.es/obref/congresos/valladolid/ponencias/unidad_diversidad_del_espanol/1_la_norma_hispanica/narbona_a.htm (12 pp.).

PASCUAL RODRÍGUEZ, J. A. y E. PRIETO DE LOS MOZOS (1998), "Sobre el estándar y la norma", en KENT, C. y M. 므. D. DE LA CALLE (eds.), Visiones Salmantinas (1898-1998). Salamanca, Universidad de Salamanca y Ohio Wesleyan University, pp. 63-95.

PRIETO DE LOS MOZOS, E. (2001), "Variación, norma y aprendizaje lingüístico", en II Congreso Internacional de la Lengua Española, Valladolid, http://cvc.cervantes.es/obref/congresos/valladolid/ponencias/unidad_diversidad_del_espanol/1_la_norma_hispanica/prieto_e.htm (15 pp.).

RAMOS, J. (2001), "En defensa del español mal hablado. El periodista en la era de las convergencias", en II Congreso Internacional de la Lengua Española, Valladolid, http://cvc.cervantes.es/obref/congresos/valladolid/ponencias/el_espanol_en_la_s ociedad/3_la_television_en_espanol/ramos_j.htm (13 pp.).

RIVAROLA, J. L. (2001), "Sobre variedades y normas del español en el marco de una cultura lingüística pluricéntrica", en II Congreso Internacional de la Lengua Espa- 
ñola, Valladolid, http://cvc.cervantes.es/obref/congresos/valladolid/ponencias/ unidad_diversidad_del_espanol/1_la_norma_hispanica/rivarola_j.htm (7 pp.).

ROJAS MAYER, E. (2001), "La norma hispánica: prejuicios y actitudes de los argentinos en el siglo XX", en Il Congreso Internacional de la Lengua Española, Valladolid,http://cvc.cervantes.es/obref/congresos/valladolid/ponencias/unidad_divers idad_del_espanol/1_la_norma_hispanica/rojas_e.htm (16 pp.).

RONA, J. P., "Normas locales, regionales, nacionales y universales en la América española", en NRFH, XXII, pp. 310-321.

TEJERA, M. J. (1984), "Estilos o registros de lengua", en Actas del VII Congreso de la Asociación de Lingüística y Filología de América Latina, II, Santo Domingo, pp. 197-216.

TUSÓN, J. (1997), Los prejuicios lingüísticos. Barcelona, Octaedro.

VAQUERO, M. (2001), "Norma, normas y lenguaje informativo. Datos de Puerto Rico", en I/ Congreso Internacional de la Lengua Española, Valladolid, http:// cvc.cervantes.es/obref/congresos/valladolid/ponencias/unidad_diversidad_del_es panol/1_la_norma_hispanica/vaquero_m.htm (16 pp.).

WAGNER, C. (1983), "La lengua formal, lengua ejemplar", en RLA, 21, pp. 129-136.

ZAMORA SALAMANCA, J. F. (1985), "Sobre el concepto de norma lingüística", en Anuario de Lingüística Hispánica, Valladolid, vol. 1, pp. 227-249. 